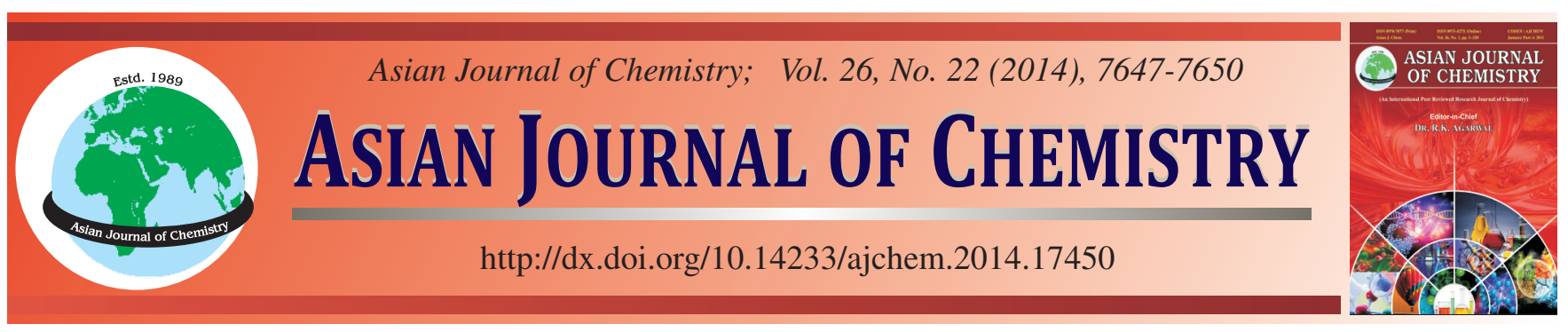

\title{
Detection of Thrombin Using Label-Free Electrochemical Aptamer Sensor Based on Bimetallic Pd-Au Nanoparticles
}

\author{
G.Y. SHEN", S.B. Zhang, X. Hu and A.G. XIAO
}

College of Chemistry and Chemical Engineering, Hunan University of Arts and Science, Changde, P.R. China

*Corresponding author: Tel: +86 736 7186115; E-mail: sgyrab@163.com

\begin{abstract}
In this paper, we reported a novel label-free electrochemical aptamer sensor based on the catalytic activity of Pd-Au nanoparticles towards $\mathrm{H}_{2} \mathrm{O}_{2}$ for the thrombin detection. In the sensing strategy, the Au electrode was first modified with Pd-Au-chitosan film and then the aptamer was immobilized on the surface of Pd-Au nanoparticles. In the presence of thrombin, the aptamer on the surface of the modified electrode would capture thrombin on the electrode interface, which makes a barrier to electro-transfer, resulting in the decreased cyclic voltammetry signals. Using this strategy, thrombin was detected within the range from 0.1 to $25 \mathrm{nM}$ with a detection limit of $0.06 \mathrm{nM}$ $(\mathrm{S} / \mathrm{N}=3)$. The aptamer sensor had a good specificity, stability and reproducibility. This simple strategy may pave a way to fabricate a simple aptamer sensors in clinical application.
\end{abstract}

Keywords: Pd-Au nanoparticles, Aptamer sensor, Label-free, Thrombin.

\section{INTRODUCTION}

Thrombin is a specific serine protease of the blood coagulation cascade that cleaves circulating fibrinogen to fibrin monomer and then polymerizes to form fibrin ${ }^{1}$. In addition to clotting disorders, thrombin can be used as a biomarker for tumor diagnosis ${ }^{2}$. Thrombin also plays a major role in vasospasm, which can often result in cerebral ischemia and infarction. Therefore, it is of great significance to develop a sensor toward thrombin detection with high sensitivity and selectivity for research and also clinical diagnosis applications.

Aptamers, artificial nucleic acid ligands, are short, singlestranded oligonucleotides (RNA or DNA) that are highly specificity and have considerable affinity with target proteins $\mathrm{s}^{3,4}$. They are also easy to synthesize, store and label at almost any desired site without loss of activity ${ }^{5,6}$. For these reasons, aptamer has been used to replace antibodies as a recognition element for the design of biosensors ${ }^{7-9}$. In recent years, the aptamerbased sandwich-type electrochemical sensors have been reported, which are labeled with enzymes including HRP7, streptavidin-alkaline phosphatase ${ }^{10}$ and pyrroquinoline quinone glucose dehydrogenase ${ }^{11}$ and quantum dots ${ }^{12,13}$. However, these aptamer-based analyses are tedious and time-consuming because of the labeling and separation steps required. Therefore, it is necessary to develop label-free electrochemical aptamer sensors for sensitive thrombin detection. Recently, nanomaterials of noble metal such as $\mathrm{Ag}^{14}, \mathrm{Pd}^{15}, \mathrm{Au}^{16}$ and $\mathrm{Pt}^{17}$ have been regarded as excellent substitutes for label materials such as enzyme due to their catalytic activities, stability and convenience of electron transfer. Furthermore, the addition of the second metal brings about strategic variations in particle size, shape, surface-morphology, composition, chemical and physical properties, bimetallic nanoparticles are of better catalysis and electrocatalysis as compared to the separate components ${ }^{18-21}$. This characteristic makes a promising prospective for developing novel enzyme-free biosensors. For example, a label-free electrochemical immunosensor based on the Pt-Au alloy nanotube was fabricated for the detection of human chorionic gonadotrophin ${ }^{22}$. Using Au-Pd nanocrystals with enhanced significant catalysis towards hydrogen peroxide, Zhao and coworkers constructed an enzyme-free electrochemical immunosensor for sensitive detection of alpha fetoprotein ${ }^{23}$. With this notion in mind, we prepared bimetallic $\mathrm{Pd}-\mathrm{Au}$ nanoparticles to fabricate a label-free aptamer sensor for the determination of thrombin. The Au electrode was first modified with Pd-Au-chitosan film and then the aptamer was immobilized on the surface of Pd-Au nanoparticles. The schematic diagram of the stepwise procedure of the aptamer sensor was shown in Fig. 1.

\section{EXPERIMENTAL}

$\mathrm{HAuCl}_{4}, \mathrm{~K}_{2} \mathrm{PdCl}_{4}$, ascorbic acid, chitosan (chit), poly(vinyl pyrrolidone), mercaptopropionic acid, human thrombin, bovine serum albumin, human immunoglobulin 


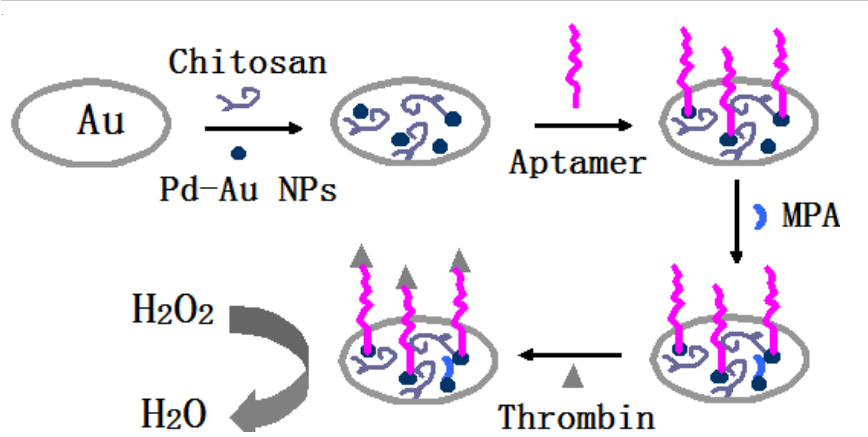

Fig. 1. Schematic illustration of aptamer sensor based on the Pd-Au nanoparticles for the detection of thrombin

$\mathrm{G}$ (IgG) and lysozyme were purchased from Sigma-Aldrich. Dilute solutions of $\mathrm{H}_{2} \mathrm{O}_{2}$ were freshly prepared daily. $0.1 \mathrm{M}$ phosphate buffer solution (PBS, pH 7) was prepared using $\mathrm{Na}_{2} \mathrm{HPO}_{4}$ and $\mathrm{NaH}_{2} \mathrm{PO}_{4}$. All aqueous solutions were prepared with doubly distilled water. The aptamers used in this study were obtained from Takara biotechnology (Dalian, China) Co. Ltd. and have the following sequences: 5'-SH-(CH2)6-TT TTT GGT TGG TGT GGT TGG-3'.

Cyclic voltammetry (CV) experiments were carried out with a CHI 660A electrochemistry workstation (Shanghai $\mathrm{CH}$ Instruments, China). A conventional three-electrode cell, consisting of a Pt electrode as counter electrode, a saturated calomel electrode (SCE) as reference electrode and an Au electrode modified with $\mathrm{Pd}-\mathrm{Au}$-chitosan film as working electrode, was used. The sizes of the Pd-Au nanoparticles were estimated with transmission electron microscopy (TEM).

Preparation of bimetallic Pd-Au nanoparticles: The bimetallic $\mathrm{Pd}-\mathrm{Au}$ nanoparticles were synthesized by using coreduction of $\mathrm{HAuCl}_{4}$ and $\mathrm{K}_{2} \mathrm{PdCl}_{4}$ method developed by Lee et $a l^{24}$. with a slight modification. Typically, $1 \mathrm{~mL}$ of a 5 $\mathrm{mM}$ aqueous solution of $\mathrm{HAuCl}_{4} / \mathrm{K}_{2} \mathrm{PdCl}_{4}$ mixtures in molar ratios of $1 / 1$ was added to $47 \mathrm{~mL}$ of purified water. Then, ascorbic acid $(100 \mathrm{mM}, 50 \mathrm{~mL})$ was added into the mixed solution. After $15 \mathrm{~s}$, an aqueous solution of poly(vinyl pyrrolidone) $(5 \mathrm{mg} / \mathrm{mL}, 1 \mathrm{~mL})$ was added dropwise with vigorous stirring. After addition, the mixture was kept stirring at $25^{\circ} \mathrm{C}$ for another $1 \mathrm{~h}$. The obtained bimetallic Pd-Au nanoparticles were collected by centrifugation at $12000 \mathrm{rpm}$ for $10 \mathrm{~min}$ and washed three times with ultrapure water. Then the product was redispersed into water for further use. Before the preparation of bimetallic Pd-Au nanoparticles, all the glass materials were cleaned with aqua regia. The TEM of bimetallic Pd-Au nanoparticles was shown in Fig. 2.

Preparation of the aptamer sensor: A gold electrode ( $4 \mathrm{~mm}$ in diameter) was polished repeatedly with 0.3 and 0.05 $\mu \mathrm{m}$ alumina slurries sequentially, followed by successive sonication in bi-distilled water and ethanol. Prior to the experiment, the gold electrode was cleaned with hot piranha solution (a 3:1 mixture of $\mathrm{H}_{2} \mathrm{SO}_{4}$ and $\mathrm{H}_{2} \mathrm{O}_{2}$, v/v) several times and then continuously scanned over a potential range from -0.3 to +1.5 $\mathrm{V}$ in freshly prepared $0.5 \mathrm{M} \mathrm{H}_{2} \mathrm{SO}_{4}$ until a voltammogram characteristic of a clean gold electrode was established. A 5 $\mathrm{mg} / \mathrm{mL}$ chitosan solution was prepared by dissolving $10 \mathrm{mg}$ chitosan in $2 \mathrm{~mL}$ of $0.1 \mathrm{M}$ acetic acid. The composition of the Pd-Au nanoparticle-chitosan mixture (Pd-Au-chit) was

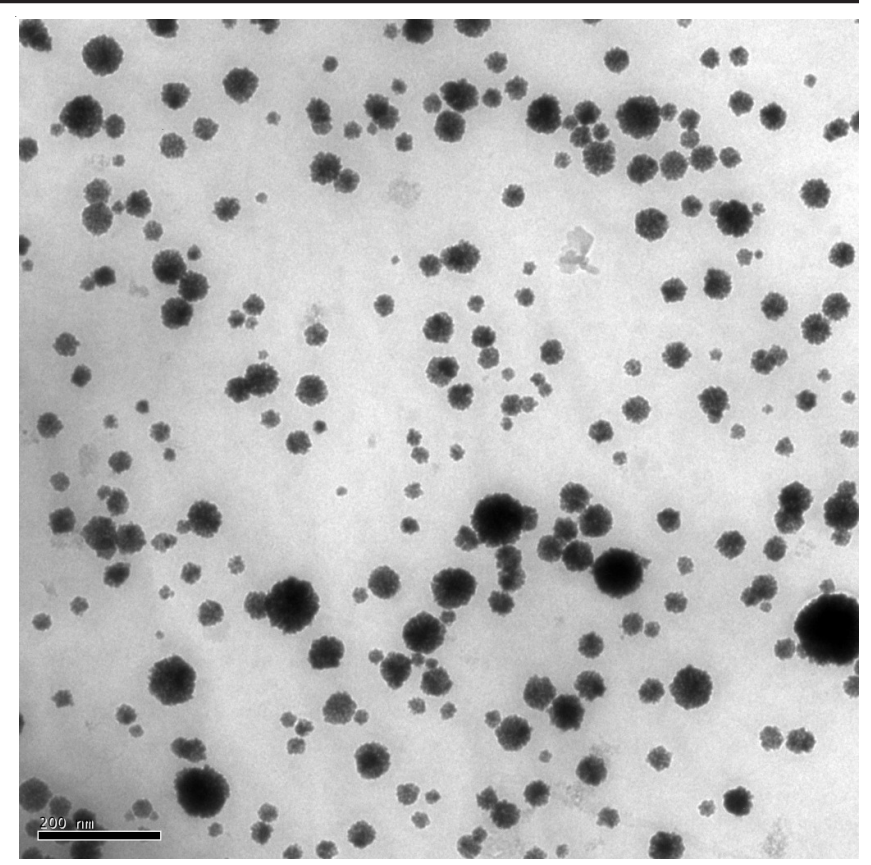

Fig. 2. TEM of bimetallic Pd-Au nanoparticles

optimized to maximize the sensor response. Pd-Au nanoparticles $(2 \mathrm{mg} / \mathrm{mL})$ and chitosan $(5 \mathrm{mg} / \mathrm{mL})$ were mixed thoroughly (in a volume ratio of 1:1) with ultrasonication for $1 \mathrm{~h}$ to get a homogeneous suspension and then $10 \mu \mathrm{L}$ of this homogeneous solution was placed on the surface of the cleaned gold electrode.

$10 \mu \mathrm{L}$ of $1 \mu \mathrm{M}$ aptamer solution diluted in $50 \mathrm{mM}$ tris$\mathrm{HCl}$ buffer (140 mM NaCl, $1 \mathrm{mM} \mathrm{MgCl}$, $\mathrm{pH}$ 7.4) was dropped on the modified electrode. When the electrode was incubated with aptamer solution overnight at $4{ }^{\circ} \mathrm{C}$, the blocking reagent mercaptopropionic acid $(10 \mu \mathrm{L}, 0.5 \mu \mathrm{M})$ was added to the surface of the gold electrode to react for $4 \mathrm{~h}$ in order to avoid the non-specific adsorption.

\section{RESULTS AND DISCUSSION}

Characterization of the modified electrode: Electrochemical impedance spectroscopy is a powerful tool for studying the interfacial properties of surface-modified electrodes. Generally, the semicircle diameter represents the electrontransfer resistance ${ }^{25}$. Fig. 3 shows the Nyquist plot of electrochemical impedance spectroscopy for the modified gold electrode in $10 \mathrm{mM} \mathrm{K}_{3} \mathrm{Fe}(\mathrm{CN})_{6} / \mathrm{K}_{4} \mathrm{Fe}(\mathrm{CN})_{6}$ solution. As can be seen from Fig. 3, the bare gold electrode had a small semicircle diameter (curve a), implying low resistance to the redox probe dissolved in electrolyte solution. After gold electrode was stepwise modified with Pd-Au-chit film (curve b), aptamer (curve c), mercaptopropionic acid (curve d) and thrombin (curve e), the semicircle diameter increased step by step. The results were consistent with the enhanced electron-transfer barriers introduced of these layers ${ }^{26}$.

Cyclic voltammetric response characteristics of the aptamer sensor: The catalytic activity of Pd-Au nanoparticles was demonstrated by $\mathrm{CV}$ experiments in $0.1 \mathrm{M}$ phosphate buffer solution ( $\mathrm{pH}$ 7.4). As can been seen from Fig. 4, CV of the electrode modified with $\mathrm{Pd}-\mathrm{Au}$-chit film in the absence of $\mathrm{H}_{2} \mathrm{O}_{2}$ was no characteristic peak (curve a). However, when 


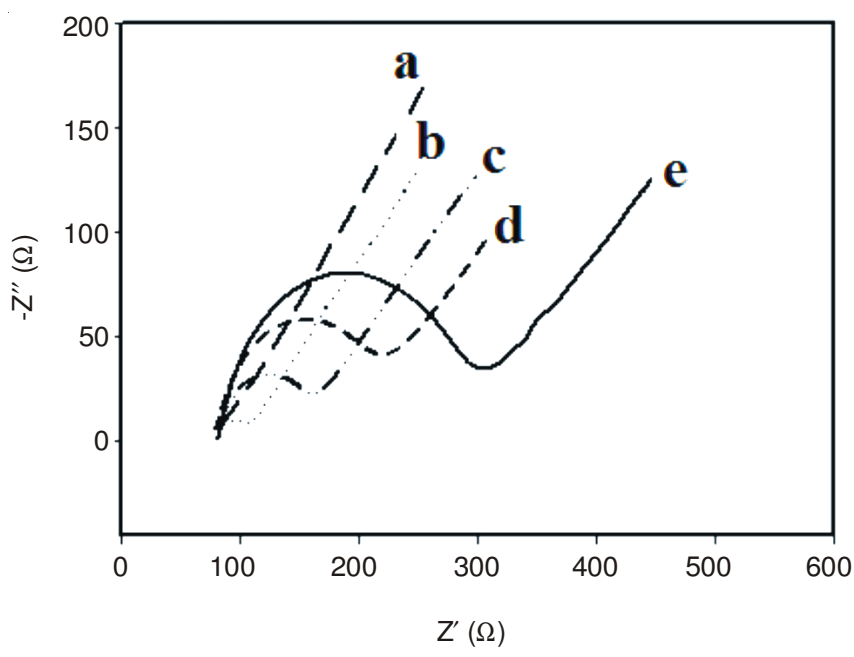

Fig. 3. Nyquist plot of electrochemical impedance spectroscopy for the modified gold electrode in $10 \mathrm{mM} \mathrm{K}_{3} \mathrm{Fe}(\mathrm{CN})_{6} / \mathrm{K}_{4} \mathrm{Fe}(\mathrm{CN})_{6}$ solution: (a) the bare electrode, (b) the modified electrode with Pd-Au-chit film, (c) with aptamer, (d) with mercaptopropionic acid and (e) with thrombin step by step. The concentration of thrombin is $5 \mathrm{nM}$

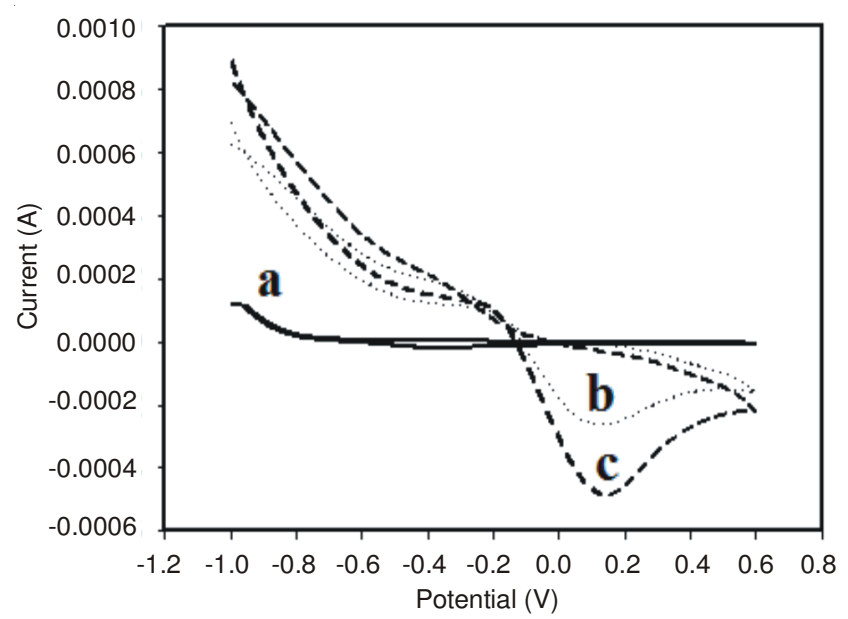

Fig. 4. Cyclovoltammetry of the electrode modified with Pd-Au-chit film in phosphate buffer solution without (a) and with (b) $5 \mathrm{mM}$, (c) 10 $\mathrm{mM} \mathrm{H} \mathrm{H}_{2}$. The concentration of thrombin is $5 \mathrm{nM}$

$\mathrm{H}_{2} \mathrm{O}_{2}$ (5 mM) was introduced into phosphate buffer solution, $\mathrm{CV}$ of the electrode modified with Pd-Au-chit film showed a characteristic peak (curve b). Moreover, the reduction current increased with the increment of $\mathrm{H}_{2} \mathrm{O}_{2}(10 \mathrm{mM})$ concentration (c). Fig. 5 showed the typical cyclic voltammograms of asprepared aptamer sensor in phosphate buffer solution containing $5 \mathrm{mM} \mathrm{H}_{2} \mathrm{O}_{2}$. As seen from Fig. 5, the concentrations corresponding to curve $\mathrm{a}, \mathrm{b}$ and $\mathrm{c}$ is 5,15 and $25 \mathrm{nM}$, respectively, the aptamer sensor exhibited a sensitive response and the response current decreased with the increasing concentration of thrombin.

Optimization pH of phosphate buffer solution: The peak current of the aptamer sensor in $0.1 \mathrm{M}$ phosphate buffer solution containing a fixed concentration of $5 \mathrm{mM} \mathrm{H}_{2} \mathrm{O}_{2}$ at different $\mathrm{pH}$ was studied from 6.5 to 8 . The experimental results showed that the optimum $\mathrm{pH}$ is 7.4. Therefore, $\mathrm{pH} 7.4$ was selected.

Calibration of the aptamer sensor: When aptamer/PdAu-chit-modified electrode was incubated with thrombin solution, specific reaction will take place between aptamer and

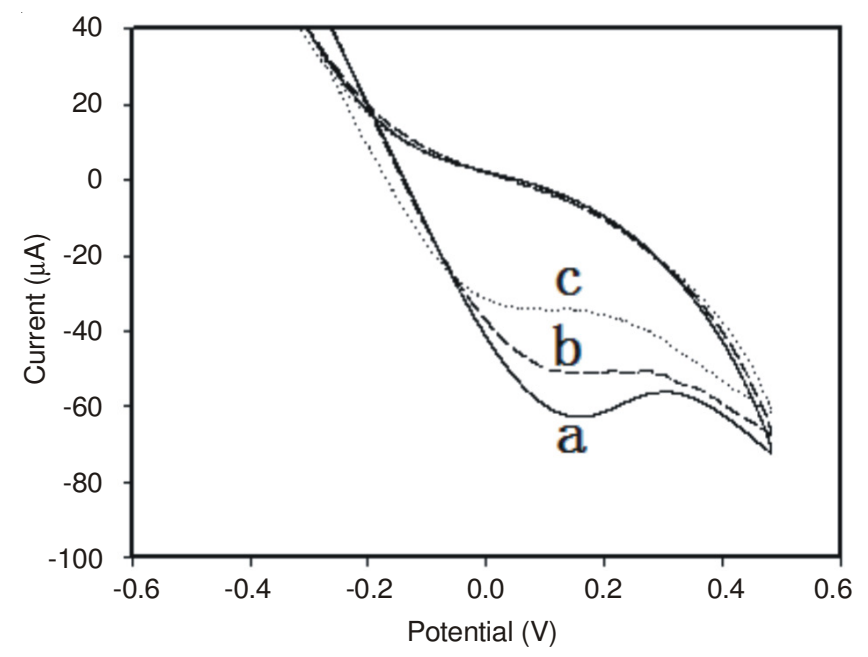

Fig. 5. Cyclovoltammetry of the aptamer sensor for the varied concentration of thrombin in phosphate buffer solution containing $5 \mathrm{mM} \mathrm{H}_{2} \mathrm{O}_{2}$ : (a) $5 \mathrm{nM}$, (b) $15 \mathrm{nM}$ and (c) $25 \mathrm{nM}$

thrombin and form the complexes on the surface of the electrode to obstruct the catalysis of Pd-Au to the reduction of $\mathrm{H}_{2} \mathrm{O}_{2}$. As expected, the peak current decreased with the increase of thrombin concentration. The calibration curve for the detection of thrombin with the proposed aptamer sensor was illustrated in Fig. 6. The linear range covered from 0.1 to 25 $\mathrm{nM}$ with a detection limit of $0.06 \mathrm{nM}$ in terms of three times standard deviation.

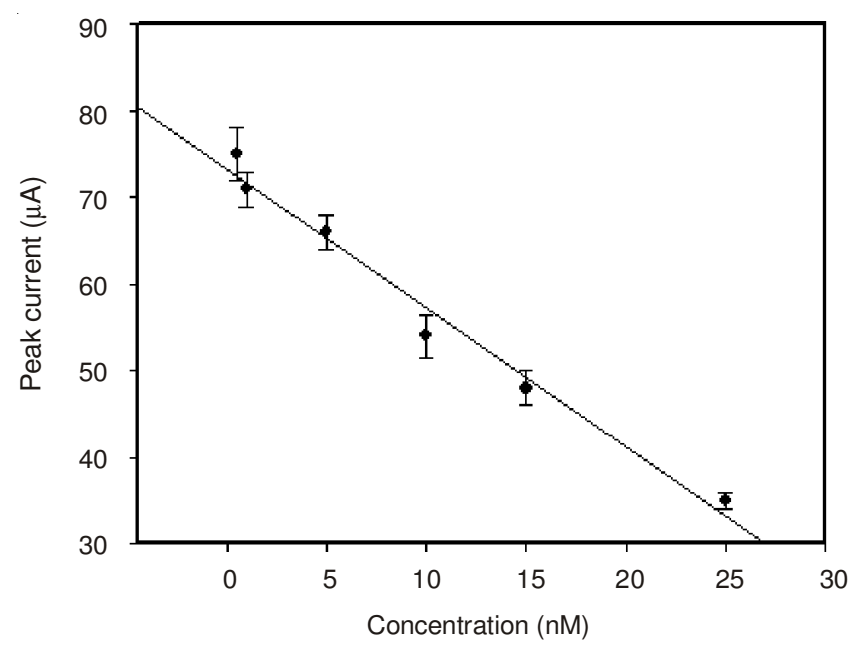

Fig. 6. Calibration curve of the proposed aptamer sensor with different concentrations of thrombin, error bars represent standard deviation, $\mathrm{n}=3$

Specificity, reproducibility and stability of the proposed aptamer sensor: The specificity of the proposed aptamer sensor was studied in this work. Three non-specific proteins (lysozyme, bovine serum albumin, human IgG) mixed with thrombin respectively were tested following the same experimental procedures. As shown in Fig. 7, the peak current responses of the aptamer sensor corresponding to the addition of bovine serum albumin $(50 \mathrm{nM})$, lysozyme $(50 \mathrm{nM})$ or human IgG $(50 \mathrm{nM})$ causes insignificant current changes compared with that of the aptamer sensor corresponding to the thrombin $(5 \mathrm{nM})$. The results demonstrated that the proposed aptamer sensor was specific to thrombin with high selectivity. The 


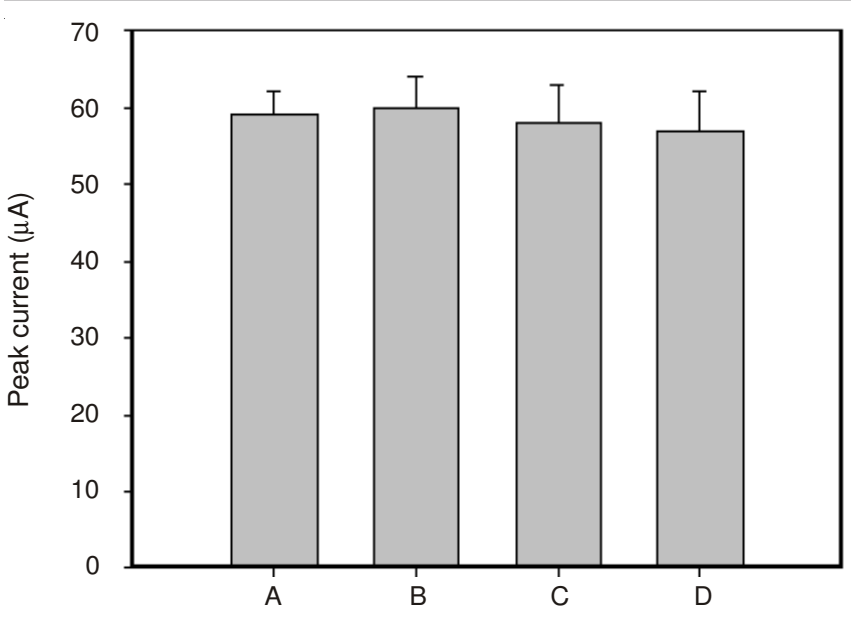

Fig. 7. Peak current of the proposed aptamer sensor corresponding to $5 \mathrm{nM}$ thrombin (a ), $5 \mathrm{nM}$ thrombin $+50 \mathrm{nM}$ lysozyme (b), $5 \mathrm{nM}$ thrombin $+50 \mathrm{nM}$ bovine serum albumin (c), $5 \mathrm{nM}$ thrombin $+50 \mathrm{nM} \mathrm{IgG} \mathrm{(d),}$ respectively. Error bars represent standard deviation, $\mathrm{n}=3$

reproducibility of the proposed aptamer sensor was examined by running six parallel experiments for $5 \mathrm{nM}$ thrombin and a relative standard deviation of $8.8 \%$ was obtained, indicating satisfactory reproducibility of the method.

The stability of the aptamer sensor was studied by the successive assays. After 50 times of CV measurements in $0.1 \mathrm{M}$ phosphate buffer solution ( $\mathrm{pH}$ 7.4) containing $5 \mathrm{mM} \mathrm{H}_{2} \mathrm{O}_{2}$, the current change of $4.6 \%$ was acquired.

Analytical application of the aptamer sensor: Thrombin is not present in the blood and plasma of healthy subjects when coagulation is not occurring ${ }^{27}$ and the physiological concentrations of thrombin in activated blood range from the grade of nanomole to micromole ${ }^{28}$. The practical applicability of the proposed aptamer sensor was studied by detecting thrombin in human serum samples. According to the standard addition method, a series of different concentration of thrombin were added into human serum samples. As shown in Table-1, the relative deviation were acceptable, suggesting that the proposed aptamer sensor has potentiality in detection of thrombin in real biological samples.

\section{TABLE-1}

DETERMINATION OF THROMBIN ADDED IN HUMAN SERUM WITH THE PROPOSED APTAMER SENSOR $(\mathrm{n}=3)$

\begin{tabular}{cccc}
\hline Samples & Added $(\mathrm{nM})$ & Founded $(\mathrm{nM})$ & $\begin{array}{c}\text { Relative } \\
\text { deviation }(\%)\end{array}$ \\
\hline 1 & 0.5 & 0.47 & -6.0 \\
2 & 5 & 5.20 & 4.0 \\
3 & 10 & 9.18 & -8.2 \\
\hline
\end{tabular}

\section{Conclusion}

In summary, we have successfully developed a label-free electrochemical aptamer sensor based on Pd-Au nanoparticles for the detection of thrombin. The determination of thrombin was based on its obstruction to the electrocatalytic reduction of $\mathrm{H}_{2} \mathrm{O}_{2}$ by $\mathrm{Pd}-\mathrm{Au}$ nanoparticles after thrombin was bound to the surface of electrode through specific reactions. Obviously, the process of preparation of the aptamer sensor is simpler than that of conventional methods. With the work presented here, we have demonstrated that the proposed aptamer sensor possesses high sensitivity, good reproducibility and stability. We anticipate that this method can be extended for the quantification of other proteins and have a potential value in clinical application.

\section{ACKNOWLEDGEMENTS}

This work was supported by the National Natural Science Foundation of China (No. 21205039) and the Construct Program of the Key Discipline in Hunan Province (Applied Chemistry).

\section{REFERENCES}

1. S.R. Coughlin, Nature, 407, 258 (2000)

2. M.L. Nierodzik and S. Karpatkin, Cancer Cell, 10, 355 (2006).

3. S. Jayasena, Clin. Chem., 45, 1628 (1999).

4. S. Clark and V. Remcho, Electrophoresis, 23, 1335 (2002).

5. R. Nutiu and Y. Li, Chem. Eur. J., 10, 1868 (2004).

6. C.K. O'Sullivan, Anal. Bioanal. Chem., 372, 44 (2002).

7. M. Mir, M. Vreeke and I. Katakis, Electrochem. Commun., 8, 505 (2006).

8. F. Le Floch, H.A. Ho and M. Leclerc, Anal. Chem., 78, 4727 (2006).

9. A.-E. Radi, J.L. Acero Sánchez, E. Baldrich and C.K. O'Sullivan, Anal. Chem., 77, 6320 (2005).

10. S. Centi, S. Tombelli, M. Minunni and M. Mascini, Anal. Chem., 79, 1466 (2007).

11. K. Ikebukuro, C. Kiyohara and K. Sode, Biosens. Bioelectron., 20, 2168 (2005).

12. H. Yang, J. Ji, Y. Liu, J. Kong and B. Liu, Electrochem. Commun., 11, 38 (2009).

13. G.D. Liu, T.M.H. Lee and J.S. Wang, J. Am. Chem. Soc., 127, 38 (2005).

14. Y. Han, J. Zheng and S. Dong, Electrochim. Acta, 90, 35 (2013).

15. J.M. You, D. Kim, S.K. Kim, M.S. Kim, H.S. Han and S. Jeon, Sens. Actuators B, 178, 450 (2013).

16. F. Meng, X. Yan, J. Liu, J. Gu and Z. Zou, Electrochim. Acta, 56, 4657 (2011).

17. H. Lu, S. Yu, Y. Fan, C. Yang and D. Xu, Colloids Surf. B, 101, 106 (2013).

18. S. Alayoglu, A.U. Nilekar, M. Mavrikakis and B. Eichhorn, Nat. Mater., 7, 333 (2008)

19. Q. Wei, Y.F. Zhao, B. Du, D. Wu, Y.Y. Cai, K.X. Mao, H. Li and C.X. Xu, Adv. Funct. Mater., 21, 4193 (2011).

20. D.S. Wang and Y.D. Li, Adv. Mater., 23, 1044 (2011).

21. D. Kim, Y.W. Lee, S.B. Lee and S.W. Han, Angew. Chem. Int. Ed., 51, 159 (2012)

22. M. Tao, X. Li, Z. Wu, M. Wang, M. Hua and Y. Yang, Clin. Chim. Acta, 412, 550 (2011).

23. L. Zhao, S. Li, J. He, G. Tian, Q. Wei and H. Li, Biosens. Bioelectron., 49, 222 (2013).

24. Y.W. Lee, M. Kim, Y. Kim, S.W. Kang, J.H. Lee and S.W. Han, J. Phys. Chem. C, 114, 7689 (2010).

25. X. Ren and P.G. Pickup, J. Electroanal. Chem., 420, 251 (1997).

26. H.Y. Liu, R. Malhotra, M.W. Peczuh and J.F. Rusling, Anal. Chem., 82, 5865 (2010).

27. H. Xu, X. Mao, Q. Zeng, S. Wang, A. Kawde and G. Liu, Anal. Chem., 81, 669 (2009).

28. C.F. Ding, Y. Ge and J.M. Lin, Biosens. Bioelectron., 25, 1290 (2010). 